\title{
O CIBERC@FE NA CONSTRUÇÃO DE UMA COMUNIDADE DE APRENDIZAGEM
}

\author{
Dra. Maria Ivone Gaspar \\ Dra. Isolina Oliveira \\ Departamento de Ensino e Educação a Distância, Universidade Aberta de Lisboa \\ \{ptivonegaspar@yahoo.com.br; isoliveira@netcabo \} \\ Dra. Patricia Alejandra Behar \\ Faculdade de Educação, Universidade Federal do Rio Grande do Sul \\ \{pbehar@terra.com.br\}
}

\section{Resumo}

O processo de desenvolvimento de uma turma de um curso de mestrado oferecido na modalidade online e na perspectiva de criação de uma comunidade de aprendizagem conduziu-nos à análise das interacções no módulo destinado à socialização dos estudantes, visando identificar as características do grupo que se ia constituindo. Dentro deste espaço a opção recaiu sobre um tópico de natureza não formal, pelo que está isento de qualquer princípio estruturante - o café (aqui designado por Ciberc@fe). Na presente comunicação, após uma 'introdução', que permitirá contextualizar a turma como o espaço da investigação desenvolvida, traça-se um quadro teórico, suportado, fundamentalmente, nos estudos de Étienne Wenger. Depois, apresenta-se o resultado da análise das interacções do grupo seleccionado e no espaço referido. Por fim, na sequência desta análise afigura-se que, num primeiro momento, a turma se identificou como uma 'comunidade de prática', para, a seguir, evoluir para uma comunidade que tem um objectivo comum: aprendizagens pré-definidas. Evidenciam-se as características da comunidade de prática, admitidas como o suporte da comunidade de aprendizagem.

Palavras - chave: aprendizagem, comunidade, interacção, partilha e prática.

\section{Introdução}

O presente estudo faz parte de um projecto que consiste em estudar e promover comunidades de aprendizagem. Tal investigação centra-se na compreensão da vida social, motivações e afectos desenvolvidos numa comunidade de prática como o início da construção de uma comunidade de aprendizagem, mais especificamente, na procura daquilo que é o constituinte das relações interpessoais no cenário de um curso de mestrado.

Tem como foco uma das edições do mestrado em Supervisão Pedagógica da Universidade Aberta de Lisboa, adequado às normas do processo de Bolonha. Esta escolha tem por base a avaliação positiva feita, pelos professores, ao desenrolar da turma que constituiu este curso. Este mestrado funciona em regime de ensino a distância na modalidade online e é oferecido segundo um modelo pedagógico, próprio da Universidade Aberta (Pereira, Quintas, Morgado, Amante \& Bidarra, 2007), que assenta, sob o ponto de vista metodológico, em três pilares: o estudo individual, a interacção e a (re)construção do saber. Este modelo torna o estudante responsável pela gestão da sua aprendizagem e, no desenrolar das atividades, dá ao professor a função de moderador. A flexibilidade do tempo e a virtualidade do espaço criam condições únicas para a adaptação às condições individuais dos estudantes que têm como ponto de partida, em qualquer das unidades curriculares do curso, a contratualidade, isto é, um instrumento, designado por "contrato de aprendizagem" que descreve os objetivos, os conteúdos e os contextos, incluindo as estratégias, os materiais e as condições e modos de avaliação. Suportado por um campus virtual, este modelo exige a criação de alguns suportes digitais, dos quais se destaca, aqui, aquele que tem por finalidade o acolhimento aos estudantes e o desenvolvimento de relações entre eles, visando competências que lhes permitam trabalhar no ambiente online; este módulo designa-se por Ambientação online e a sua estrutura integra vulgarmente um espaço social, designado aqui por ciberc@fe. Os estudantes conhecem as funcionalidades da plataforma, o ambiente de trabalho e aplicam as ferramentas que lhe estão disponíveis. No final do período que é dedicado a este módulo devem manifestar, claramente: (i) destreza na utilização das funcionalidades que experimentaram na plataforma e (ii) facilidade na relação com os outros, evidenciando atitudes interativas e preocupação em estabelecer e desenvolver desafios. 
Dentro deste módulo, seleccionou-se o fórum CiberC@fe destinado ao encontro informal, livre de qualquer tipo de plano, sendo, apenas, orientado para a convivência entre os estudantes, onde podem conversar sobre vários aspectos, nomeadamente da sua vida social e cultural.

Sendo aquele o grupo e este o contexto que se constitui no objecto do estudo que se apresenta, decidiu-se analisar as interacções desenvolvidas no fórum CiberC@fe, a partir de um conjunto de itens. Tais itens têm como referência as dimensões de prática como propriedade das comunidades apresentadas por Wenger (1998). Entendemos, pois, que se estes alunos se constituírem numa comunidade de prática, iniciarão, entretanto, o caminho para a comunidade de aprendizagem. Este artigo desenvolve-se a partir de três pontos. Num primeiro ponto, iremos ao encontro da teoria para, no segundo ponto, apresentarmos os dados recolhidos a partir da análise das interações no fórum. Como reflexões finais, evidenciaremos os passos que indicam o caminho na passagem de uma 'comunidade de prática' para uma 'comunidade de aprendizagem'.

\section{Encontro com a teoria}

A primeira questão que se coloca prende-se com o significado de comunidade. Ela corresponde a um modo de ser e estar, que, aliás, assume, em comum, a mesma orientação. É no por em comum que surge a comunidade, tornando-se um espaço que vincula e integra, pelo que proporciona vida e, como tal, deverá ser um todo orgânico. Embora a sua aparição se deva justificar por fins diversos e a sua constituição possa obedecer a matrizes diferentes, apresenta três características centrais no conceito de comunidade: a comunhão dos objectivos, o envolvimento mútuo em crenças e sentimentos comuns e a partilha nas tarefas. É a comunidade que gera confiança mútua e um clima estimulador (Ribeiro, Silva, Boff \& Vicari, 2011).

Na raiz da palavra comunidade estará a palavra latina comunicare, daí a essência do significado de comunidade seja a comunicação. As principais estratégias de comunicação, adoptadas por uma comunidade correspondem à interacção, ao predomínio da participação horizontal, à comunicação dialógica e à assunção de compromissos mútuos. É na aplicação destas estratégias, clarificadas na linguagem que se vai tornando comum e se torna um dos elementos unificadores e construtores de identidade, que situamos a 'comunidade de prática'.

$\mathrm{O}$ desenvolvimento chave do conceito subjacente à comunidade de prática tem lugar no trabalho de Lave e Wenger ${ }^{1}$ (1991) a partir de três pressupostos ${ }^{2}$ que explicita (i) 'o domínio' ou seja o campo de actuação, aquilo que lhes dá conteúdo "é o motivo pelo qual as pessoas se reúnem , ou seja, a temática tratada no grupo" (Ribeiro et al., 2011, p. 694); (ii) 'a comunidade' - um conjunto de pessoas envolvidas por interesses comuns e (iii) 'a prática' - assumida pela partilha dos repertórios das suas experiências ou de novos conhecimentos, pois "representa o conhecimento que é desenvolvido, compartilhado e mantido" (Ribeiro et al., 2011, p. 695).

Wenger, McDermott e Snyder (2002) indicam sete princípios, a respeitar, no cultivo de comunidades de prática: (i) desenho aberto, com flexibilidade para adaptação às mudanças; (ii) diálogo; (iii) interacção; (iv) níveis de participação conscientes; (v) participação valorizada; (vi) combinações de familiaridade e espontaneidade; (vii) ritmo da comunidade.

E, com base nestes princípios, os mesmos autores destacam três etapas no desenvolvimento das mesmas comunidades: (i) Formação - a etapa em que a comunidade se inicia, nela se identificam interesses comuns e se formam as relações. Nesta fase é muito importante demonstrar o valor potencial da comunidade para os participantes. (ii) Integração nesta etapa a comunidade vai fazendo um processo de maturação, define tempos concretos, intercambiando, co-construindo o conhecimento e desenvolvendo as suas próprias formas de

\footnotetext{
1 - Lave, J. And Wenger, E. (1991) Situated learning: Legitimate Peripheral Participation. Cambridge University Press; UK.

2 - Wenger, Etienne (2006). Communities of Practice - a brief introduction. In http://www.ewenger.com/theory/index.htm consulta em 27.02.2010
} 
colaboração. (iii) Transformação - a última etapa pode ser uma etapa em que a comunidade desaparece, ou se formaliza ou evolui para uma nova comunidade.

Num outro trabalho, Wenger (1998) identifica três aspectos essenciais à identificação da comunidade de prática: (i) compromisso mútuo (ou identidade) - a comunidade emerge em torno de acções e ideias comuns e define-se em função da interacção, ou seja aquilo a que mais tarde chamou 'domínio'; (ii) empresa conjunta (ou objectivos) - além da responsabilidade partilhada, Wenger enfatiza a partilha dos objectivos, cuja renegociação contínua, identifica uma das razões da existência da 'comunidade', dando-lhe o sentido de existir; (iii) repertório partilhado (ou contexto) - este elemento inclui todos os comportamentos da comunidade: rotinas, processos, conceitos, símbolos, etc. que a comunidade adquire ao longo da sua existência (pode entender-se como uma cultura comum), por outras palavras, aquilo que é o objecto da 'prática'.

Considerámos estes aspectos como as dimensões da comunidade de prática e a partir delas definimos os itens que constituem a grelha de análise dos fóruns: criação de atmosfera amigável; estado de espírito; pedido de ajuda/como fazer; outros (onde entram "aspectos organizacionais"); informação específica.

Importará, entretanto, uma referência à 'comunidade de aprendizagem' centralizada, naturalmente, no conceito de aprendizagem. Gavriel Salomon ${ }^{3}$ apresenta cinco etapas ou estádios estruturantes da comunidade de aprendizagem e que identifica com: (i) Acesso e motivação - etapa que corresponde ao início dos trabalhos, pois os membros da comunidade são situados no contexto que lhes é apresentado; é-lhes descrito o tipo de trabalho que lhes é pedido e são motivados para que adiram. (ii) Socialização - nesta etapa, os membros da comunidade criam laços de união e vão construindo o seu estilo de relação, na interacção e no sentido de pertença ao grupo; (iii) Troca de informação - é a etapa de pesquisa, de estudo, de recolha, selecção e tratamento da informação. (iv) Construção do conhecimento, etapa em que os membros da comunidade dão visibilidade ao conhecimento que vão assumindo significativamente; (v) Desenvolvimento - a etapa que mostra resultados em 'crescimento' efectivo e em que, casuisticamente, os membros da comunidade estão sujeitos a uma renegociação contínua.

Se comparamos os dois tipos de comunidades - de prática e de aprendizagem, poderemos observar o quadro seguinte:

Quadro III - Etapas de desenvolvimento da 'comunidade de aprendizagem' e da 'comunidade de prática'

\begin{tabular}{|l|l|}
\hline \multicolumn{1}{|c|}{$\begin{array}{c}\text { Comunidades de Prática } \\
\text { Etapas de Wenger, Mcdermott e Snyder }\end{array}$} & $\begin{array}{l}\text { Comunidades de Aprendizagem } \\
\text { Etapas de Salomon }\end{array}$ \\
\hline 1. Formação & $\begin{array}{l}\text { 1. Acesso e motivação } \\
\text { 2. Socialização }\end{array}$ \\
\hline 2. Integração & $\begin{array}{l}\text { 3. Troca de informação } \\
\text { 4. Construção do conhecimento }\end{array}$ \\
\hline 3. Transformação & 5. Desenvolvimento \\
\hline
\end{tabular}

Note-se, num primeiro momento, que nos dois tipos de comunidades analisados, encontram-se três estratégias comuns: a participação horizontal, a comunicação dialógica e o compromisso mútuo. Poder-se-á afirmar que em qualquer destas comunidades se desenvolve aprendizagem contextualizada na participação e na interacção; acrescente-se que, também, em ambos os tipos de comunidades, se constrói conhecimento.

\footnotetext{
${ }^{3}$ Citado por Kate Hawkey (2003).
} 
Ao apontar as suas diferenças, poderão notar-se algumas divergências no sentido atribuído a algumas características, tendo presente a razão da existência de um e de outro tipo das comunidades em referência.

A comunidade de prática surge espontaneamente na sequência de um interesse ocasional, e/ou fortuito; não obedece, à partida, a uma programação mas consciencializa os objectivos que justificam a sua existência; ela tem uma natureza informal, abarca um conceito lato, com profunda generalização, de aprendizagem. É um tipo de comunidade não estruturada mas que apresenta uma identidade (marcada pelas ideias e acções comuns), tem objectivos comuns que vai renegociando de modo a manterem o consenso e evidencia um contexto que corresponde à cultura comum dos seus membros (expressa na palavra e na acção).

A comunidade de aprendizagem surge dentro de uma programação formal e a sua designação deve-se à principal finalidade que a determina: aprender. Logo ela é constituída com contornos definidos e limites de acção traçados. Este tipo de comunidade surge, evolui e dissolve-se em função do processo de aprendizagem que a envolve. Assim, tem um tempo de duração previsto e que se inclui na própria planificação. Tem tarefas específicas, entre as quais se destaca a recolha, pesquisa, selecção e tratamento de informação, em atitude de partilha, com alguma atenção à estratégia do trabalho em grupo e à acentuação de 'aprender a aprender' e 'aprender a comunicar', na prossecução de três objectivos gerais: desenvolver a capacidade de raciocínio, facilitar a expressão do pensamento e incrementar a resolução de problemas. Estamos perante uma aprendizagem não só formal mas também estruturada.

Em síntese a 'comunidade de prática' e a 'comunidade de aprendizagem' apresentam em comum: (i) partilha de interesses, de informação e de conhecimentos; (ii) definição e consciencialização dos objectivos que prosseguem; (iii) atitude dialógica; (iv) sentimento de pertença à comunidade e (v) identificação, através do compromisso mútuo. As grandes diferenças, entre estes dois tipos de comunidade, registam-se: (i) na natureza da aprendizagem (formal nas comunidades de aprendizagem e informal nas comunidades de prática); (ii) na natureza da acção (estruturada nas comunidades de aprendizagem e não estruturada nas comunidades de prática) (iii) na natureza dos objectivos (previamente definidos e visando a sua prossecução, nas comunidades de aprendizagem, enquanto emergem, situacional ou ocasionalmente, nas comunidades de prática).

A aprendizagem é um conceito complexo e implica experiência adquirida, novidade e contextualização. Segundo Jean Lave ${ }^{4}$, a aprendizagem é uma função cultural, pelo que terá de ser sempre situada, ou seja, contextualizada no interior da cultura em que ocorre. Na teoria cognitivista distinguem-se, entre outras, a perspectiva construtivista, que não considera $o$ conhecimento como um dado adquirido, estabelecido e transmissível; defende que, pelo contrário, o conhecimento é algo pessoal e que o seu significado é construído pela pessoa em função da experiência acumulada; a perspectiva ausebeliana para a qual o conhecimento é entendido como uma rede que se representa por mapas conceptuais e quanto melhor sedimentada e mais forte for a rede melhor serão compreendidos e assumidos os conceitos e a perspectiva vigotskiana que vê no trabalho colaborativo um modo de melhor consecução da aprendizagem.

Considera-se, então, a aprendizagem como um processo social mediante o qual os aprendentes, em contexto, constroem significados que resultam, entre outros factores, da interligação entre o conhecimento previamente adquirido e as novas experiências realizadas.

\section{Interacções nos fóruns}

No presente estudo procedeu-se à análise de interacções ocorridas em diferentes fóruns e, em particular, no espaço designado por Ciberc@fé, que foi criado com a intenção de provocar a socialização online. Entendemos aplicar a metodologia própria da análise etnográfica, tendo

\footnotetext{
${ }^{4}$ - Lave, J. \& Wenger, E. (1991). Situated learning: legitimate peripheral participation. Cambridge USA: Cambridge University Press (cit. Fino, 2004).
} 
em conta que ela pretende explicar os processos sociais envolvidos num dado cenário, através de uma descrição detalhada de episódios observados (Mercer, Littleton \& Wegerif, 2009). Os dados etnográficos foram recolhidos durante o período de ambientação online num fórum criado para o efeito no conjunto de outros fóruns, como já foi referido. Recorda-se que, paralelamente, os estudantes participavam noutros fóruns, nomeadamente, num fórum organizado segundo um conjunto de actividades propostas visando o conhecimento e o desenvolvimento de competências sobre ser estudante online.

Os participantes são principalmente professores do ensino básico e secundário, mas também formadores, cujas idades oscilam entre os 26 e 51 anos de idade. A turma, a funcionar em sala virtual, era constituída por 22 estudantes, 15 do género feminino e 7 do género masculino e pela coordenadora do curso e focámos a análise das interacções que decorreram no fórum CiberC@fé no período de tempo de 16 de setembro a 10 de outubro de 2007

Os estudantes tinham tido uma sessão presencial durante um dia mas anteriormente não se conheciam. Não tendo, este fórum, nem tópicos nem actividades de discussão previstos. Os estudantes são os responsáveis por introduzir os temas e iniciar o debate em torno dele.

\subsection{Análise dos dados}

Foram analisados os posts dos estudantes e da coordenadora do curso, num total de 621 . Uma primeira leitura de todas as participações seguida de leituras posteriores permitiu delinear "unidades de significado" cujo conteúdo ou "tema" é restaurado por sumarização ou transformação numa linguagem mais abstracta. O objectivo da análise é encontrar temas comuns, principalmente, aqueles que ilustram o significado do fenómeno, o processo de envolvimento mútuo (ou não) na construção de uma comunidade online.

As unidades de significado que revelaram semelhanças foram agrupadas. O diálogo com os dados tornou possível a descrição a um nível específico que, por comparação, fez emergir a identificação de uma "estrutura fundamental do fenómeno" (Tesch, 1990). Os resultados descrevem os constituintes através dos quais é compreendida a experiência humana que está a ser estudada, ou seja, como é que o espaço CiberC@fé contribuiu para a construção de uma comunidade de aprendizagem. Interessava perceber quais são as dimensões da prática e como se relacionam no sentido de construção de uma comunidade de aprendizagem. Como é que os participantes se envolveram na discussão? Qual o papel jogado por cada um dos participantes? Há responsáveis pelo manutenção do diálogo? Como se revela o compromisso mútuo? Como se constitui o reportório que é partilhado?

\subsection{Conexões temáticas no CiberC@fé}

A análise incidiu sobre 621 posts colocados pelos participantes durante o período correspondente à ambientação online. No quadro I pode observar-se que todos os estudantes participaram, mas há dez que se destacam pelo número de posts publicados em relação aos restantes doze, cujo número de participações foi inferior a vinte. Com efeito, no tal de 22 estudantes, 10 são responsáveis por cerca de $80 \%$ das participações.

Quadro I - Distribuição do número de posts pelos estudantes
\begin{tabular}{|c|c|}
\hline $\mathrm{N}^{\mathbf{o}}$ de posts & $\mathrm{N}^{\mathbf{o}}$ de estudantes \\
\hline $0-20$ & 12 \\
\hline $21-40$ & 5 \\
\hline $41-60$ & 2 \\
\hline $61-80$ & 1 \\
\hline $81-100$ & 2 \\
\hline
\end{tabular}

Os temas de conversação, num total de 67 temas (cinco com início por parte da coordenadora) foram agrupados segundo as categorias seguintes: a) Criação de atmosfera amigável incluindo todos os posts que apelam à conversação sobre livros, artigos de jornais, 
poesia, anedotas ou, então, que fazem propostas de descanso, de pausas para café ou ouvir música; b) Informação específica sobre aspectos tecnológicos (em especial sobre o funcionamento da moodle) ou sobre acontecimentos surgidos nos media; c) estado de espírito tem a ver com os sentimentos manifestados pelos participantes, em particular, alegria, insatisfação ou surpresa; d) Pedido de ajuda que remete para a solicitação de ajuda sobre como fazer algo (a maior parte das vezes relacionado com as ferramentas da moodlle); e) Outras que agrupou dois posts que convidavam à introdução de uma certa organização na conversação no CiberC@fé.

A análise do quadro II evidencia como é que os participantes procuraram criar relações interpessoais sustentadas não só na procura de possíveis identificações de gostos através de várias propostas e divulgação de episódios e acontecimentos partilhados apelando à manifestação de opiniões, mas também através da revelação de sentimentos. A disponibilização de informações várias, principalmente sobre questões técnicas relacionadas com a moodle e as suas ferramentas e o pedido de ajuda são também constituintes desses nós de relações interpessoais. Sublinham-se dois posts relacionados com a tentativa de estruturar a discussão no fórum (Como funciona o CiberCafé? e Metodologia - será que aqui pega?) publicados pelo mesmo participante no início e já no decorrer do fórum, mas que não suscitaram continuidade no debate.

Quadro II - Incidência dos temas conversacionais

\begin{tabular}{|l|c|}
\hline \multicolumn{1}{|c|}{ Temas/tópicos } & $\mathrm{N}^{\circ}$ de temas \\
\hline $\begin{array}{l}\text { Criação de atmosfera amigável (boas-vindas, humor, poesia, } \\
\text { gostos, passatempos, propostas de descanso, de leitura de } \\
\text { artigos, livros, visionamento video youtube, })\end{array}$ & 38 \\
\hline Informação específica (aspectos técnicos, acontecimentos) & 14 \\
\hline $\begin{array}{l}\text { Estado de espírito (cansaço, alegria, satisfação, surpresa, } \\
\text { frustação...) }\end{array}$ & 8 \\
\hline Pedido de ajuda/como fazer & 5 \\
\hline Outros (aspectos organizacionais) & 2 \\
\hline Total & 67 \\
\hline
\end{tabular}

Dos 67 temas de conversação nem todos foram agregadores de opiniões, de trocas e partilha de pontos de vista, ou seja, nem todos provocaram envolvimento mútuo. Há um conjunto alargado de temas $(n=14)$ que despoletaram posts encadeados envolvendo quase todos os participantes. Contudo, há 7 temas que foram desencadeadores de um certo compromisso e identificação por parte de todos os participantes e que marcam o desenvolvimento da comunidade. Passamos a enunciar cada um dos temas, procurando ilustar com intervenções dos estudantes nos respetivos fóruns.

A. Esta plataforma onde os participantes se manifestam frustrados com a lentidão da plataforma; o comentário colocado pelo estudante A surge como uma proposta, na sequência de algumas dificuldades manifestadas por alguns sobre o uso da plataforma:

Da leitura e volume dos nossos comentários, no meu anterior post, verifico que muitos não têm muita segurança no uso da plataforma. Daí venho propor à Prof. M. A criação de mais um tópico na nossa disciplina dedicado exclusivamente a esta questão (...) . (estudante A).

B. Um país de gente tonta?, título de um artigo de opinião sobre os trabalhos de casa e que um dos participantes apropria para provocar o debate sobre esses assuntos. 
C. Ora aqui estou eu..., que inicia um tema dedicado à descrição do que o participante está a fazer no momento e que foi continuado pelos outros, tal como se evidencia:

Olá a todos

Mais um dia a terminar, ou não, e ainda resta alguma energia para tomar um café. A abertura do ano escolar está a deixar todos de rasto . Os pais a reclamarem por tudo e por nada, os colegas, os alunos a ocupação plena dos tempos escolares, activ. Enriquec. Curricular... Ufa!!! Ainda bem que posso tomar um café convosco. (estudante F.)

D. Confessionário, um post que apela a que os participantes falem de si, quem são verdadeiramente, ilustrado com o diálogo entre os estudantes B e O:

Isto de sermos colegas e de tentarmos conhecer-nos melhor, tem muito que se lhe diga... tem, tem!

Não é possível darmo-nos bem se não conhecermos os gostos pessoais uns dos outros.

E. Sala de fumo, momento de descontracção que resulta do lançamento da ideia de criação de uma sala de fumo virtual:

(...) a propósito queres o café com açucar ou adoçante? (estudante A)

Olá, também tomo um! Enquanto não entrarmos num mínimo de rotina isto é muito violento. (estudante MJ)

F. Passagem administrativa, já, momento de humor em que o participante expressa um desabafo sobre o mau funcionamento da plataforma e que é continuado no mesmo tom pelos restantes participações, tal como se ilustra através das intervenções dos estudantes $\mathrm{P}$ e A:

Estive com tanta dedicação a escrever um texto para o cybercafé, mas a internet pregoume uma partida: desligou-se... desde que começou a trovoada tem sido assim... para a próxima faço um copy do texto, para não sofrer esta tristeza!

(...) está muito lenta, transformando uma simples deslocação a este café num exercício de paciência mais próprio de quem espera em fila por um autocarro atrasado.

G. Vai uma desgarrada (49 posts) corresponde à ultima intervenção no fórum onde uma participante apela a que se inicie uma desgarrada e em que todos colaboraram com diversos posts.

Deste modo, o processo de desenvolvimento da comunidade assenta num conjunto de temas que emergem da interação entre os vários participantes e que consubstanciam a autoorganização da comunidade. Esses temas correspondem a passos importantes em termos do envolvimento mútuo traduzido na tensão criada pela utilização da plataforma mas também e, principalmente, pela criação de um ambiente harmonioso através de tagarelice e desafios como foi o apelo à desgarrada, o que se revelou no número e na diversidade de formas que a participação assumiu. 
A análise das interações permite também destacar o papel que o participante A desempenhou no desenvolvimento das relações interpessoais. Com efeito, apesar de não ser o participante com maior número de posts colocados, emerge na comunidade como o líder a quem os restantes participantes recorrem com frequência apelando ao seu humor, afectividade e ao conhecimento técnico e da vida social. A sua participação evidencia-se através da capacidade de configurar a prática da comunidade pelas intervenções específicas com pessoas específicas, colocando no centro a negociação de significado.

\section{Considerações finais}

Entre as várias designações encontradas no vocabulário de cada língua, para o termo comunidade, consideramos, neste contexto, tão só aquelas que se situam nas proximidades da "aprendizagem". Na sequência desta preocupação, seleccionaram-se dois tipos de comunidades - "comunidades de prática" e "comunidades de aprendizagem" - cuja distinção se procura estabelecer pela descrição das principais características de uma e outra.

A 'comunidade de prática' identificada caminha para uma 'comunidade de aprendizagem'. Neste sentido, a aprendizagem entende-se como um processo que pressupõe a participação social, implica o envolvimento de cada um com o outro e dispõe algo em comum.

Atende-se à comunidade em instituições formais, onde surge e actua, quer em espaço real quer em espaço virtual; a distinção das características destes espaços é feita pelas formas de comunicação utilizadas e, no caso virtual, assenta na utilização das ferramentas previstas pela Internet com a aplicação de sistemas de redes.

Referimos já que a comunidade de prática se desenvolve no percurso de três etapas Formação, integração e transformação e constatámos que o processo dos estudantes no fórum em análise percorreu estas etapas. Percebemos como a aprendizagem no fórum CyberC@fe, integrado no módulo "Ambientação online", produz prática como uma estrutura emergente (Wenger, 1998). O desenvolvimento da prática requer tempo mas, tal como foi evidenciado neste estudo, o que define a comunidade de prática é a sustentação conseguida à custa de um envolvimento mútuo na prossecução de um objectivo em conjunto, partilhando histórias de aprendizagem. Tornou-se, também, evidente o processo de auto-organização que correspondeu ao percurso de cada estudante numa atitude de partilha e de construção com os outros. Os participantes começaram a ultrapassar as três etapas - formação, integração e transformação quando se tornaram capazes de construir conhecimento e de questionar-se sobre aspectos organizacionais. Interessa, então, investigar qual é a tendência evolutiva desta comunidade, que dá sinais de transformação, na presunção de que está num ambiente virtual marcado pelo elearning no âmbito de um curso estruturado - um mestrado - que se insere no contexto, marcado pelo modelo pedagógico que assume .

\section{Referências Bibliográficas}

GASPAR, I., OLIVEIRA, I., BEMHAJA, B., SANTOS, G., DÂMASO, M., \& VISEU, N., (2009). Estudante online: que competências?. In Proc. The Seventh Open Classroom Conference. EDEN - Porto.

HAWKEY, Kate (2003). Social Constructivism and Asynchronous Text-Based Discussion: A Case Study with Trainee Teachers. Hingham: Kluwer Academic Publishers.

LAVE, J.; WENGER, E. (1991) Situated learning: Legitimate Peripheral Participation. Cambridge: Cambridge University Press. 
MERCER, N., LITTLETON, K., \& WEGERIF, R. (2009). Methods for Studying the Process of Interaction and Collaborative Activity in Computer-Based Educational Activities. In K. Kumpulainen, C. E. Hmelo-Silver \& M. César (Eds.), Investigating Classroom Interaction (pp. 27-42). Roterdam: Sense Publishers.

PEREIRA, A, MENDES, A. Q., MORGADO, L., Amante, L., BIDARRA, A. (2007). Universidade Aberta's Pedagogical Model for Distance Education: A University for the Future. Lisboa: Universidade Aberta.

RIBEIRO, A. M., SILVA, J. L. T., BOFF, E. \& VICCARI, R. M. (2011) . Dos Ambientes de Aprendizagem às Comunidades de Prática (pp- 690-699). In Anais do XXII SBIE - XVII WIE, Aracaju, 21 a 25 de novembro de 2011.

TESCH, R. (1990). Qualitative research: analysis types and software tools. London: Falmer.

WENGER, E. (2006). Communities of Practice - a brief introduction. In http://www.ewenger.com/theory/index.htm consulta em 27.02.2010.

WENGER, E. (1998). Communities of Practices. Cambridge: Cambridge University Press.

WENGER, E., McDEMOTT, R., SNYDER,W. (2002). Cultivating communities of Practice: A guide of managing knowledge. Cambridge: Harvard Business Scholl Press. 